\title{
Dose-dependent Changes After Proton and Photon Irradiation in a Zebrafish Model
}

\author{
SZILVIA BRUNNER ${ }^{1 *}$, TÜNDE TŐKÉS ${ }^{1 *}$, EMÍLIA RITA SZABÓ ${ }^{1}$, RÓBERT POLANEK ${ }^{1}$, \\ IMRE ZOLTÁN SZABÓ ${ }^{1}$, ZITA REISZ ${ }^{2,3}$, BARBARA KONCZNÉ GUBÁN ${ }^{4}$, ANDRÁS LAJOS SZIJÁRTÓ ${ }^{5}$, \\ MICHAEL BRAND $^{6}$, STEFAN HANS ${ }^{6}$, LEONHARD KARSCH $^{7,8}$, ELISABETH LESSMANN ${ }^{8}$, \\ JÖRG PAWELKE ${ }^{7,8}$, MICHAEL SCHÜRER $^{9}$, ELKE BEYREUTHER ${ }^{7,8}$ and KATALIN HIDEGHÉTY ${ }^{1,10}$ \\ ${ }^{1}$ ELI-ALPS, ELI-HU Non-Profit Ltd., Szeged, Hungary; \\ ${ }^{2}$ Department of Pathology, University of Szeged, Szeged, Hungary; \\ ${ }^{3}$ Department of Clinical Neuropathology, King's College Hospital, London, U.K.; \\ ${ }^{4}$ Department of Dermatology and Allergology, University of Szeged, Szeged, Hungary; \\ ${ }^{5}$ Department of Medical Physics and Informatics, University of Szeged, Szeged, Hungary; \\ ${ }^{6}$ Center for Regenerative Therapies Dresden (CRTD), Technische Universität Dresden, Dresden, Germany; \\ ${ }^{7}$ OncoRay - National Center for Radiation Research in Oncology, Faculty of Medicine and University Hospital Carl \\ Gustav Carus, Technische Universität Dresden, Helmholtz-Zentrum Dresden-Rossendorf, Dresden, Germany; \\ ${ }^{8}$ Helmholtz-Zentrum Dresden-Rossendorf, Dresden, Germany; \\ ${ }^{9}$ National Center for Tumor Diseases (NCT), Dresden, Germany; \\ ${ }^{10}$ Department of Oncotherapy, University of Szeged, Szeged, Hungary
}

\begin{abstract}
Background/Aim: The importance of hadron therapy in the cancer management is growing. We aimed to refine the biological effect detection using a vertebrate model. Materials and Methods: Embryos at 24 and $72 \mathrm{~h}$ postfertilization were irradiated at the entrance plateau and the mid spread-out Bragg peak of a $150 \mathrm{MeV}$ proton beam and with reference photons. Radiation-induced DNA doublestrand breaks (DSB) and histopathological changes of the eye, muscles and brain were evaluated; deterioration of specific organs (eye, yolk sac, body) was measured. Results: More and longer-lasting DSBs occurred in eye and muscle cells due to proton versus photon beams, albeit in different numbers. Edema, necrosis and tissue disorganization, (especially in the eye) were observed. Dose-dependent morphological deteriorations were detected at $\geq 10$ Gy dose levels, with relative biological effectiveness between $0.99 \pm 0.07$ (length) and $1.12 \pm 0.19$ (eye). Conclusion:
\end{abstract}

*These Authors contributed equally to this study.

Correspondence to: Szilvia Brunner, ELI-ALPS, ELI-HU NonProfit Ltd., Wolfgang Sandner Str. 3., H-6728 Szeged, Hungary. Tel: +36 706202117, Fax: +36 62550191, e-mail: Szilvia.Brunner@elialps.hu

Key Words: Proton, photon, zebrafish embryo model, DNA-DSB, morphological malformations, histological changes.
Quantitative assessment of radiation induced changes in zebrafish embryos proved to be beneficial for the radiobiological characterization of proton beams.

The role of radiotherapy (RT) has recently become more pronounced in complex cancer management for reasons including earlier diagnosis through comprehensive screening programs and advanced imaging; technological developments allowing highly selective dose deposition to oligometastatic diseases (1); or novel approaches of immunoRT (2). In the last decades, the growing availability of hospital-based proton facilities has made it possible to include proton therapy as a highly selective radiation modality in the anticancer therapeutic strategy. Therefore, preclinical research on the pathomechanism of action, on the biological effectiveness and on the potential improvement of the therapeutic index is of high interest.

Heavy charged particles such as protons and heavier ions slow down in human tissues with maximum dose deposition at the track end, in the so-called Bragg peak (3). Recent results support the clinical advantage gained from the favourable depth dose distribution and the significant decrease in integral dose in normal tissues, compared to the best photon techniques, especially in terms of side effects and secondary cancer induction $(4,5)$. The biological effectiveness of a proton beam is higher than that of the reference photon radiation, and an average constant relative biological effectiveness (RBE) of 1.1 is applied clinically. 
However, RBE can vary between 1.0 and 1.6 depending on the proton energy (position at the beam path in depth), the dose, the biological system, the endpoint and on assessment accuracy $(6,7)$.

Ongoing technological developments provide new charged particle acceleration methods that yield beams with parameters, such as ultrahigh dose rate, pulsed operation and extremely small non-divergent beams. Examples are laserdriven particle beam therapy (8), FLASH therapy (9), Micro Beam therapy (10) and combined modalities (11). Prior to human application, it is essential to establish the safety of a novel modality and to define the potential toxicity profile and the basic pathomechanism of action. Several organdependent preclinical tests were introduced, such as the skin's reaction system in pigs and mice, murine acute upper intestinal crypt regeneration test (12), rodent lung pneumonitis assay, oral mucosa reaction and rat spinal cord damage (13-15). These pig and rodent model based tests are accepted as reliable for the assessment of the biological effectiveness of high linear energy transfer (LET) radiation with changing parameters (dose rate, fractionation), and for the comparison of different nonconventional radiation qualities and specific biological properties of different ion species, e.g. helium and carbon (15). However, considerable controversy has recently emerged over the use of mammals on a wider scale (animal rights issues, the translationality of the data and heterogeneity of responses). The establishment of a high throughput, reliable in vivo model is very important in the era of rapid technological development in radiation oncology. The National Institute of Health (NIH) proposed the zebrafish as the third vertebrate model (after mice and rats) for studying human diseases (16), because of their homology with the human genome $(70 \%)$, and the similarity of the main signalling pathways, morphological structure and function to those of mammals (17). Therefore, we introduced the zebrafish embryo model as a small vertebrate system for radiobiology investigations (18).

In previous experiments, we had determined the appropriate biological parameters of the zebrafish system for radiobiology investigations. Then, we validated this vertebrate model for the measurement of RBE values of different LET beams and combined modalities $(19,20)$. In the previous work, a dose threshold of about 10 Gy was found for the induction of morphological abnormalities and for reducing embryonic survival within four days postirradiation (dpi) (19). To better understand this threshold, more detailed investigations on cellular, histopathological and molecular level were subjected to embryos preserved from the previous campaign. Additionally, our aim is to define parameters and standards most suitable for radiobiology investigations on the zebrafish embryo model and unlock the potential of the proposed vertebrate model for the analysis of refined quantitative endpoints.

\section{Materials and Methods}

The methods and materials of the original irradiation experiments are described in detail in (19), and a brief summary is given below. The experiments were performed using wild type $\mathrm{AB}$ zebrafish (Danio rerio) embryos at the age of $24 \mathrm{~h}$ postfertilization (hpf) and $72 \mathrm{hpf}$. All procedures were carried out in compliance with EU Directive 2010/63/EU on the protection of animals used for scientific purposes. The document states that early life-stage zebrafish embryos, up to five days postfertilization (as long as they are not able to feed independently) are not protected, therefore experiments using embryos under this age do not require ethical approval. All procedures were performed in accordance with this directive, as well as with German legislation on the care and use of laboratory animals. Zebrafish embryos were provided by the Center for Regenerative Therapies at Technische Universität Dresden. Embryos were washed, sorted into E3 medium (21) and transported for irradiation between 21 and $22 \mathrm{hpf}$ under the appropriate temperature conditions. The embryos were kept at room temperature $\left(23^{\circ} \mathrm{C}\right)$ until irradiation. Shortly before treatment, the developmental stage of the embryos was checked by microscopic observation (Axiovert S100, Zeiss, Germany), and the embryos were randomly allocated to the treatment groups (96 per dose, radiation quality, repeat). The embryos were paired in the inner 48 wells of a 96-well plate (Sigma-Aldrich Chemie GmbH, Munich, Germany), which were filled with $200 \mu \mathrm{lE} 3$ medium. The plates were transported and stored in polystyrene boxes outside the laboratory. Immediately before irradiation, the plate covers were removed, and the wells were sealed to prevent E3 leakage during irradiation. Control samples were prepared and treated in parallel with the test samples but were not irradiated. After irradiation, the embryos were separated so that each embryo was kept in a separate well. They were checked under microscope and maintained under normal conditions $\left(28^{\circ} \mathrm{C}\right)$.

On the fourth dpi, the embryos were sacrificed and fixed in $4 \%$ paraformaldehyde for histological analysis. For immunohistochemical evaluations, the embryos were irradiated at $72 \mathrm{hpf}$ and were frozen on dry ice at $30 \mathrm{~min}, 60 \mathrm{~min}$ and $24 \mathrm{~h}$ after irradiation.

Proton and photon irradiation. Proton irradiations were performed at the horizontal fixed-beam beamline of the experimental area of University Proton Therapy Dresden. The implemented doublescattering system (22) was optimized for $150 \mathrm{MeV}$ protons and the delivery of $10 \times 10 \mathrm{~cm}^{2}$ homogeneous proton fields. An in-house developed water-filled phantom (23) was applied to position the 96well plates in a reproducible and precise manner (with a positioning accuracy of $\pm 0.2 \mathrm{~mm}$ ), i.e., positioned at the entrance plateau and in the middle of the spread-out Brag peak (mSOBP). For absolute dosimetry we applied a Markus ionization chamber (model 34045, PTW, Freiburg, Germany; $1.06 \mathrm{~mm}$ water equivalent thickness of the entrance window) at sample position, and Gafchromic EBT3 films (ISP Corp., New York, USA) in front of each sample. The zebrafish embryos were treated with graded doses of $5 \mathrm{~Gy}, 10 \mathrm{~Gy}$ and $15 \mathrm{~Gy}$ at a dose rate of $5 \mathrm{~Gy} / \mathrm{min}$ at both positions.

The water phantom was also used for the $6 \mathrm{MV}$ photon reference irradiation with the clinical linear accelerator ARTISTE (Siemens, Erlangen, Germany), which was turned for horizontal beam delivery. For practical reasons, the plates were irradiated at the same depth in the phantom like those treated at the proton entrance plateau with doses of 5 to 15 Gy delivered at a dose rate of 2.86 $\mathrm{Gy} / \mathrm{min}$ as measured with a semiflex ionization chamber (model 31010 , PTW) at the sample position. 
Brunner et al: Proton Irradiation in Zebrafish Embryos

Table I. Evaluation aspects of the semi-quantitative scoring system from 0 to 3 points (Figures 4, 5 and 6).

\begin{tabular}{|c|c|c|c|c|}
\hline Score & 0 & 1 & 2 & 3 \\
\hline Eye & Intact, normal layers & $\begin{array}{l}\text { Normal layers, but smaller } \\
\text { eye and lens, incidence } \\
\text { of lenticulopathia }\end{array}$ & $\begin{array}{l}\text { Moderate disorganization } \\
\text { of the layers, reduction of the } \\
\text { eye and lens size, lenticulopathia }\end{array}$ & $\begin{array}{c}\text { Severe layer disorganization, } \\
\text { eye and lens shrinkage, } \\
\text { lenticulopathia }\end{array}$ \\
\hline Muscle & $\begin{array}{l}\text { Intact, normal pattern of } \\
\text { the longitudinal muscles }\end{array}$ & Mild necrosis & $\begin{array}{l}\text { Necrosis, inordinated } \\
\text { muscle fibers }\end{array}$ & $\begin{array}{l}\text { Severe necrosis, loss of cell } \\
\text { nuclei, edema between the } \\
\text { inordinated muscle fibers }\end{array}$ \\
\hline Brain & $\begin{array}{l}\text { Intact layers, normal } \\
\text { distribution of nuclei }\end{array}$ & $\begin{array}{c}\text { Presence of vacuolization } \\
\text { in cell layers }\end{array}$ & $\begin{array}{l}\text { Edema, tissue } \\
\text { disorganization }\end{array}$ & $\begin{array}{l}\text { Edema, tissue disorganization, } \\
\text { severe necrosis }\end{array}$ \\
\hline
\end{tabular}

Detection of ionizing radiation-induced $\gamma$-H2AX formation. For the analysis of DNA double strand breaks (DNA-DSB) 72 embryos were irradiated at the age of $72 \mathrm{hpf}$, whereof each one third was frozen at $30 \mathrm{~min}, 60 \mathrm{~min}$ and $24 \mathrm{~h}$ post-irradiation. The frozen embryos were sectioned, dried, fixed, equilibrated and prepared for staining. We used the Foxp3/transcription Factor Staining Buffer Set [Fixation/permeabilization concentrate + Permeabilization diluent + Permeabilization buffer (eBioscience, Thermofischer Scientific, USA)]. The samples were incubated with fixation/permeabilization concentrate and diluent (1:3, Thermofischer Scientific) for $20 \mathrm{~min}$ at room temperature. Then we applied $1 \mathrm{x}$ working of permeabilization reagent diluted with distilled water (1:9, Thermofischer Scientific) for $5 \mathrm{~min}$ at room temperature. This was followed by washing with phosphate buffered saline (PBS, $3 \times 5 \mathrm{~min}$, Sigma-Aldrich, USA). We blocked the reaction with $1 \%$ goat serum (Sigma Aldrich) added to $1 \%$ bovine serum albumine (BSA)-PBS buffer, which also included $0.025 \%$ Triton X-100 (Sigma-Aldrich). This step lasted $30 \mathrm{~min}$ at room temperature. After fixation/permeabilization and blocking, we tipped off the excess buffer and added primary mouse phospho-histone H2AX (Ser 140) monoclonal antibody (3F2, Thermofischer Scientific, diluted 1:100, in $0.5 \% \mathrm{BSA}$ in PBS $+0.025 \%$ Triton X-100), to each section, which were then incubated overnight $\left(4^{\circ} \mathrm{C}\right)$. After several washes $(3 \times 5 \mathrm{~min})$, the sections were incubated with goat anti-mouse IgGAlexa 647 (1:500, Thermofischer Scientific) for $90 \mathrm{~min}$ at room temperature in the dark, and were washed again several times, and the nuclei were then stained with DAPI (1:100, Sigma Aldrich) dissolved in $0.05 \mathrm{M}$ PBS. After several rounds of washing, the sections were mounted with Fluoromount-G (Thermofischer Scientific) and 10 samples ( 1 sample $=1$ embryo) per group were analyzed by confocal microscopy (Zeiss LSM880, Zeiss) at a magnification of $40 \times$. Pictures were recorded and evaluated by two observers. The foci were counted in 100 cell nuclei in both the eye and the tail muscle tissue cells in the control in the photon and proton irradiated groups. The field of view (FOV) was randomly selected by the investigators on the same coded section. We normalized the foci number of the irradiated groups to the mean value of the corresponding controls.

Histological analysis. Forty-eight zebrafish embryos per group were fixed at the age of $120 \mathrm{hpf}$ in $4 \%$ paraformaldehyde solution; they were then paraffin embedded, sectioned and stained with standard hematoxylin and eosin. The histological changes of the different tissues were evaluated by light microscopy (AXIO Observer Z1 Inverted Microscope, Zeiss, Germany) on 10 embryos per group. All sections were scanned, and every sample was evaluated offline at 20x magnification by Panoramic Viewer (3DHISTECH, 1.15.4) and Case Viewer Softwares (3DHISTECH, 2.2, - Ltd. Budapest, Hungary). Each tissue type was subjected to semi-quantitative scoring and was characterized by a score corresponding to the severity of the histological damage in the range of 0 to 3 (Table I). The evaluation was performed in coded sections by two independent investigators.

Evaluation of the morphological changes. On the third and fourth dpi, photographs were taken of each embryo to observe the macroscopic developmental changes for the given radiation qualities. After checking the image quality, we could include 709 images in the analysis using a code system, where the observers were blinded to both radiation quality and dose. Using the software Image $\mathrm{J}$ [Fiji version $1.15 \mathrm{n}(24)]$, we manually measured the length of the embryos (from the tip of the head to the end of the spine) as a parameter of growth delay and spinal curvature, the diameter of the eyes as a parameter of abnormal eye development (microphthalmia), and the diameter of the yolk sac as a marker of edema formation (Figure 1), respectively.

Determination of RBE of morphological malformations. The yolk sac diameter increased due to more severe radiation response, we calculated the RBE based on the following formula:

$$
\mathrm{RBE}=\frac{\text { Structure diameter after } 15 \text { Gy proton }}{\text { Structure diameter after } 15 \text { Gy photon }}
$$

In the case of radiation impeded body and organ development invers calculation of RBE were applied, relating the average structure size (body length, eye size) obtained for certain proton and photon dose groups, respectively.

$$
\mathrm{RBE}=\frac{\text { Structure size after } 15 \mathrm{~Gy} \text { photon }}{\text { Structure size after } 15 \text { Gy proton }}
$$

Uncertainties of the RBE were derived by error propagation based on the standard deviations of the average malformation rates.

Statistical analysis. This study includes three independent experiment replications. Data analysis was performed with the statistical software packages SigmaStat for Windows (Jandel Scientific, Erkrath, Germany) or StatView 4.53 for Windows (Abacus Concept Inc., 29 Berkeley, CA, USA). For the 


\section{a} b

C

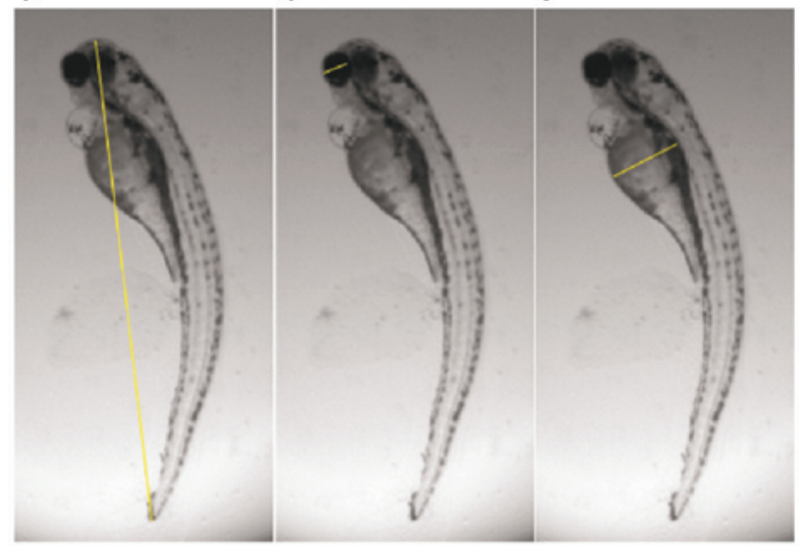

Figure 1. Macroscopic alterations observed at 15 Gy dose level and measured by (a) the distance between the two endpoints of the embryo from the tip of the head to the end of the spine, (b) the largest diameter of the eye, (c) the transversal diameter of the yolk sac.

morphological and histological evaluation, differences between the groups were analyzed with Kruskal-Wallis one-way ANOVA on ranks, followed by Dunn's method for pairwise multiple comparison. In the Figures and Results, median values $(\mathrm{M}), 75^{\text {th }}$ (p75) and $25^{\text {th }}$ (p25) percentiles are given. For immunohistological evaluations Student's $t$-test was used followed by the Mann-Whitney Rank Sum Test. Values $p<0.05$ was considered statistically significant.

\section{Results}

DNA damage: Detection of the number of $\gamma-H 2 A X$ foci. In (non-irradiated) control embryos 1-2 foci per FOV were detected in the muscle and 2-3 foci per FOV in the eye, respectively, that were used to normalize the measured $\gamma$ $\mathrm{H} 2 \mathrm{AX}$ foci in the irradiated samples. For proton irradiation at $\mathrm{mSOBP}$ and plateau position neither the number of $\gamma$ $\mathrm{H} 2 \mathrm{AX}$ foci, nor its time dependent decrease showed a significant difference in each type of tissue we examined. Independent of radiation quality and tissue type a significant increase in the number of DNA-DSB was found after 5 Gy dose delivery at $30 \mathrm{~min}$ after irradiation as compared to the (non-irradiated) control group. At each time point the number of foci in the eye cells was three times higher than in the muscle cells, whereas the difference of the relative number of DNA-DSB foci between the proton and photon radiation was significant in both tissues. For example, in the muscle cell nuclei, a significantly higher number of foci was found $30 \mathrm{~min}$ after proton irradiation (12.98 \pm 1.63$)$ as compared to photon treatment $(6.29 \pm 1.70)$. In case of the eye cells, significant differences between the proton $(49.02 \pm 3.94)$ and photon groups $(13.34 \pm 4.57)$ (Figure 2) were also detected at $30 \mathrm{~min}$ after irradiation. The number of DNADSBs remarkably decreased after further $30 \mathrm{~min}$ : by $50 \%$ a $\quad$ EYE
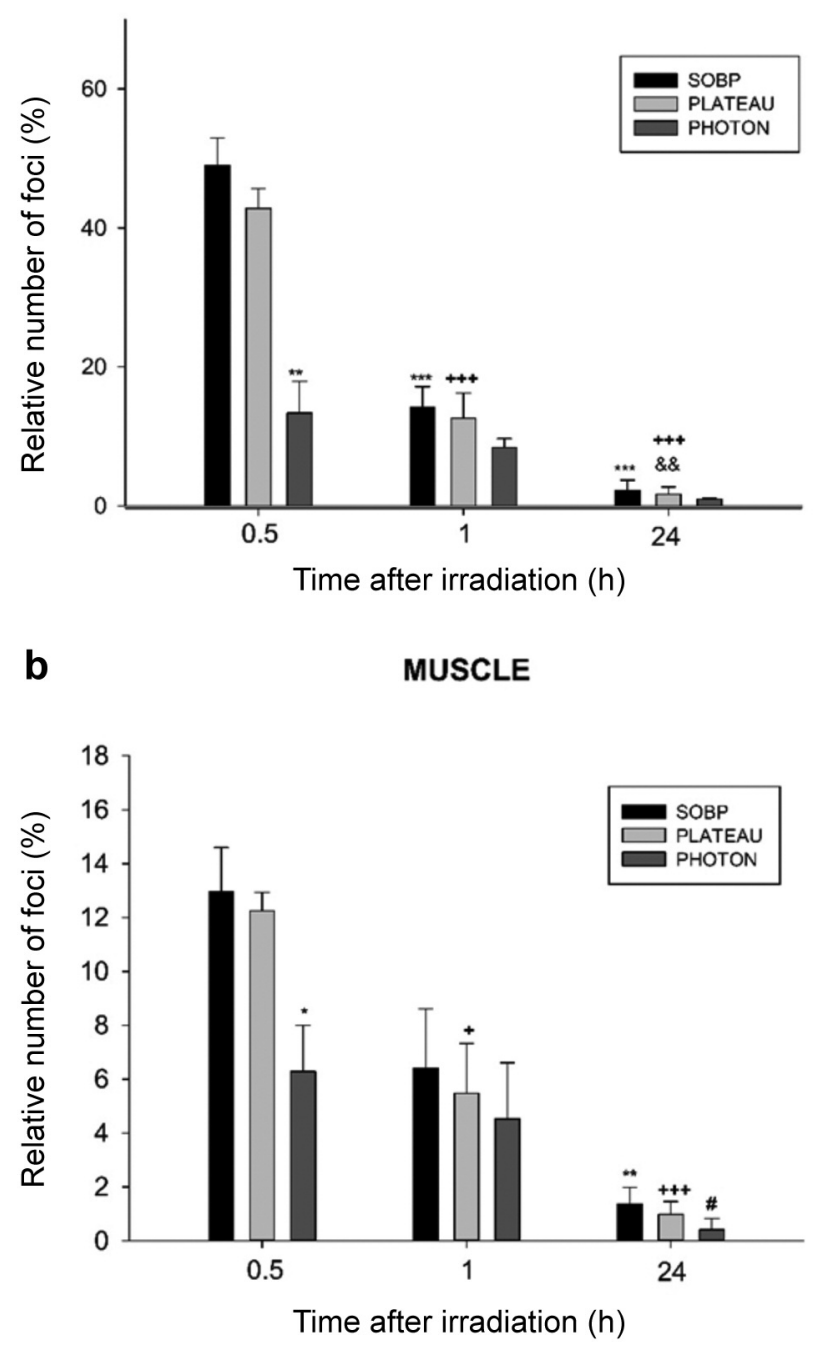

Figure 2. Kinetics of $\gamma-H 2 A X$ foci appearance. The graph displays the number of foci per cell as a function of time after irradiation (a) in the eye $(b)$ in the tail muscle. Statistics: Student's t-test, Mann-Whitney rank test $p<0.05$ was considered statistically significant; $* * p<0.01$ and $* * * p<0.001$ relative to the spread out of Bragg peak (SOBP) group at $30 \mathrm{~min},{ }^{+} p<0.05$ and ${ }^{+++} p<0.001$ relative to the Plateau group at 30 $\mathrm{min}, \& \& p<0.01$ relative to the Plateau group at $60 \mathrm{~min}, * p<0.05$ and ${ }^{* *} p<0.01$ relative to the $S O B P$ group at $30 \mathrm{~min},{ }^{*} p<0.05$ relative to the Photon group at $30 \mathrm{~min}$.

and $44 \%$ after proton and photon irradiation in the muscle cells, and by $70 \%$ and $40 \%$ after proton and photon irradiation in the eye cells. After $24 \mathrm{~h}$ the number of foci in the photon irradiated samples almost returned to the preirradiation level. Although the number of foci decreased with time after proton irradiation too, we could still detect a significant number of unrepaired DNA-DSBs, especially in the muscle cells (Figures 2 and 3). 
a Eye

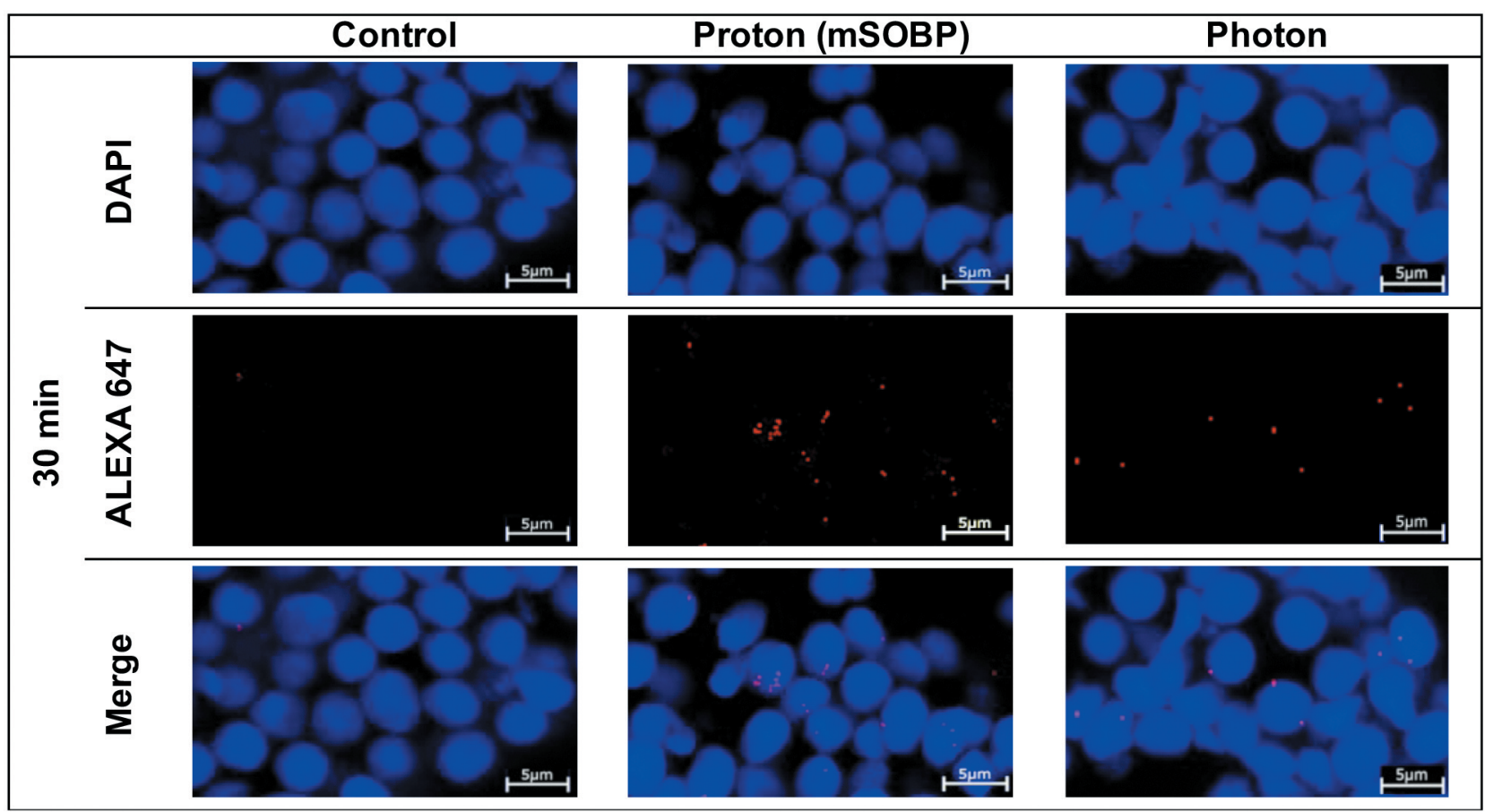

b Muscle

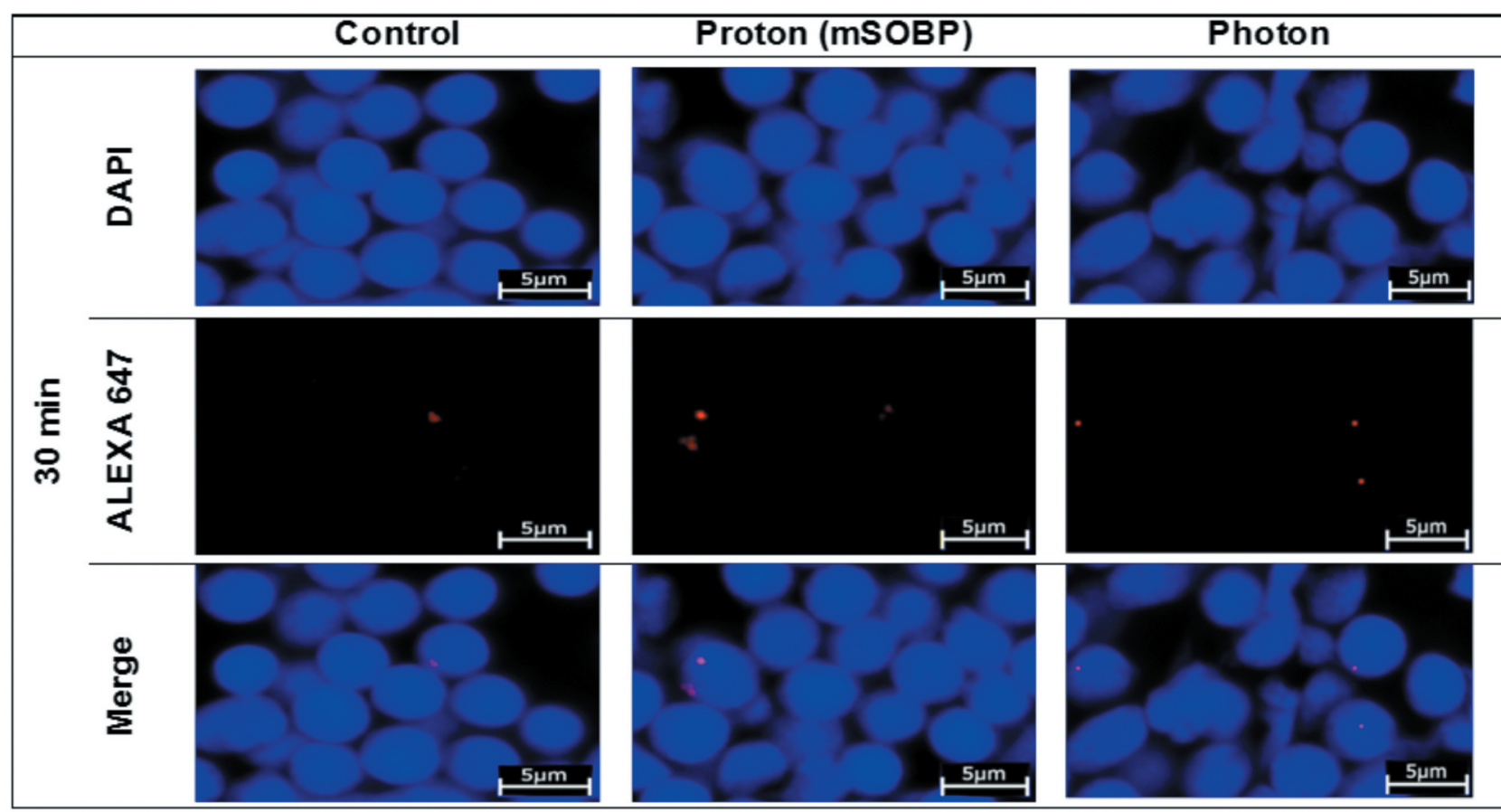

Figure 3. Illustrative images of immunohistochemical analysis of $\gamma$-H2AX foci by confocal microscopy in the eye (a) and the tail muscle (b). DNA (DAPI staining) and $\gamma$-H2AX foci (red dots, Alexa 647) are merged to detect $\gamma$-H2AX foci within the cell nuclei of control (left) and 30 min after treatment with 5 Gy of mid of spread out of Bragg peak protons (middles) and photons (right). Scale bars=5 $\mu \mathrm{m}$. 
a

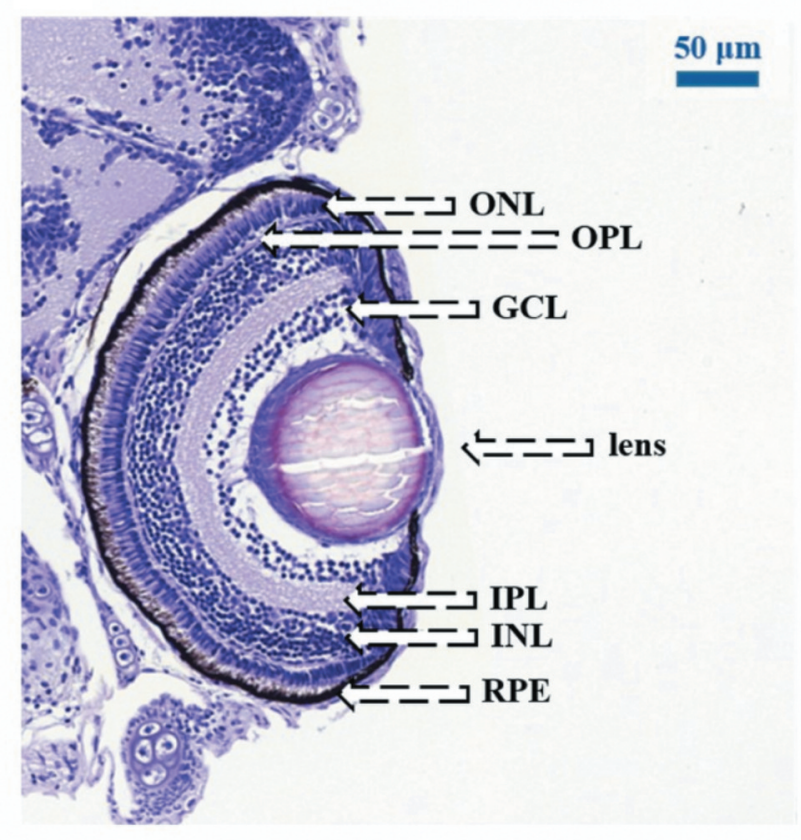

b

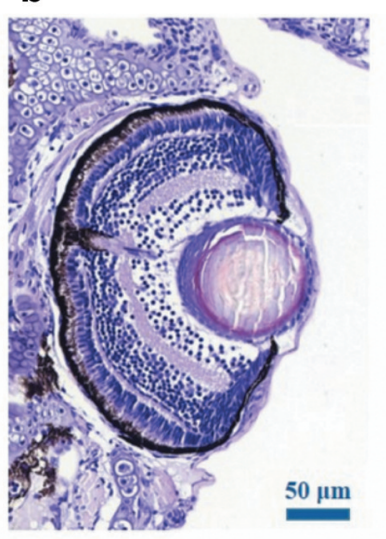

d

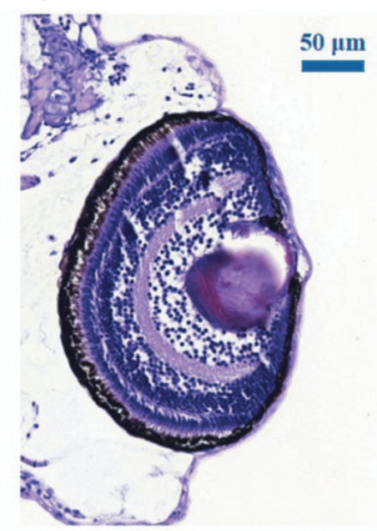

C

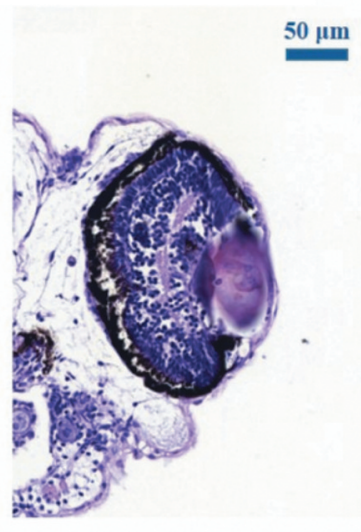

e

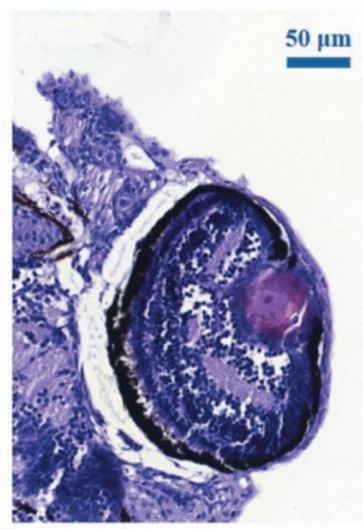

Figure 4. Dose-dependent changes in the eye size after photon and proton irradiation. Hematoxylin and eosin stained coronal retinal sections of untreated zebrafish embryos (a) after treatment with (b) $10 \mathrm{~Gy}$, (c) 15 Gy of $6 \mathrm{MV}$ photons and with (d) 10 Gy, (e) 15 Gy protons, respectively, all captured at $120 \mathrm{~h}$ postfertilization. The images show characteristic stratification of nuclear and plexiform layers. After $10 \mathrm{~Gy}$ and $15 \mathrm{~Gy}$ photon and proton irradiation, the samples show widespread retinal degeneration with loss of lamination and irregular patchy islands of plexiform tissue, with absence of large areas of retinal pigment epithelium (RPE). The structure of the cataractous lens is tightly compacted, the loss of the layers of photoreceptor cells severe retinal damage with pyknotic nuclei, RPE hypertrophy and atrophy. Further layers are indicated as follows: GCL: Ganglion cell layer; INL and ONL: inner and outer nuclear layer, respectively; IPL and OPL: inner and outer plexiform layer, respectively. Scale bars=50 $\mu m$.

Semi-quantitative analysis of embryo histopathology. The histological findings reveal that the degree of cellular disorganization in the eye is dependent on dose, but independent of the applied radiation qualities (Figure 4). Compared to the normal eye, the organization of the eye was not disrupted after 5 Gy irradiation, but both the eye and the lens decreased in size, and first signs of lenticulopathy became noticeable in some samples. After $10 \mathrm{~Gy}$ the changes are more pronounced with non-concentrically organized retina layers. Even more serious damage could be observed after 15 Gy radiation: it was difficult to distinguish most of the remaining highly disorganized cellular layers, the inner plexiform layer was nearly absent and the prominent round nuclei of the ganglion cell layer could not be discerned. Finally, radiation resulted in incipient lens opacification already at 5 Gy dose level, and cataract formation progressed at 10 Gy and 15 Gy dose levels.

Normally, the tail muscle is composed of pink longitudinal fibres, and the nuclei are in the middle of the fibres. Irrespective of radiation quality, 5 Gy irradiation result in no visible damage, whereas a sign of mild necrosis was detected after 10 Gy irradiation (Figure 5). At higher doses the muscle fibre structure is destroyed: dystrophy causes fibres elongation, the nuclei are lost, and the fibres become darker, which is a sign of hypereosinophilisation. Interstitial fluid was detected between the muscle fibres, which can be associated with inflammatory pathway activation induced by free oxygen radicals released as a result of irradiation (25). All these processes led to the development of muscle necrosis, which could be observed later or at higher dose levels. 


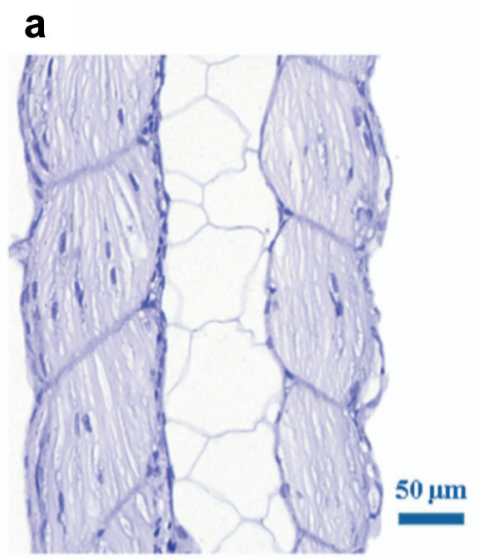

b

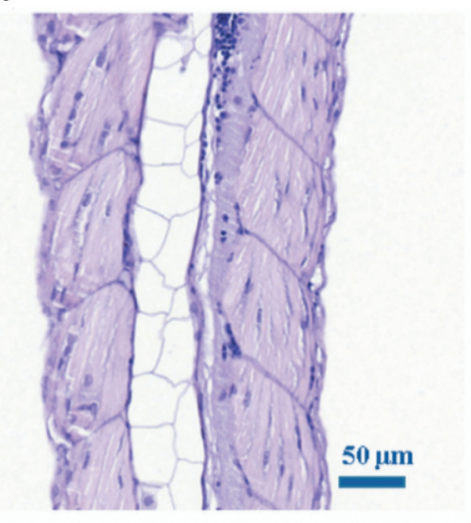

d

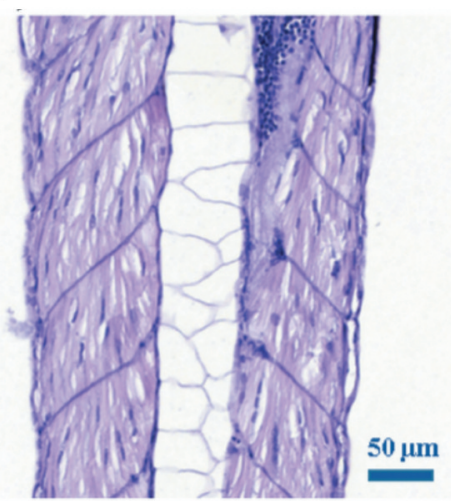

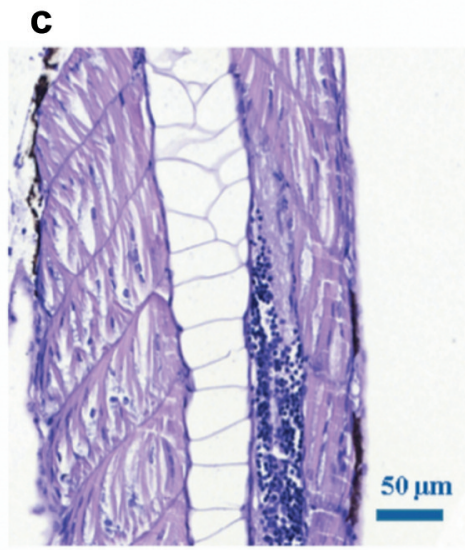

e

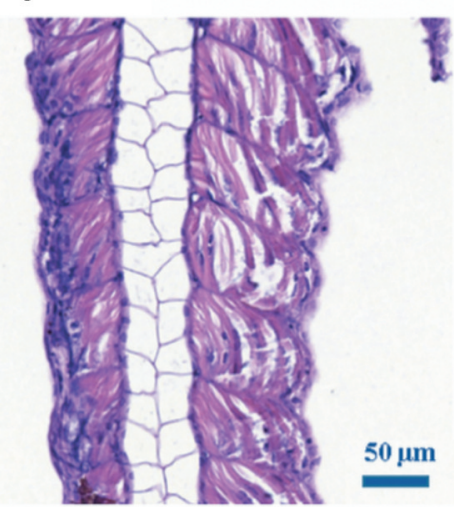

Figure 5. Dose-dependent changes in the muscle after photon and proton irradiation. Hematoxylin and eosin stained coronal sections of wild type zebrafish tail muscles at 120 h postfertilization (a) control, (b) 10 Gy photon irradiated, (c) 15 Gy photon irradiated, (d) 10 Gy proton irradiated and (e) 15 Gy proton irradiated embryos. The pictures show longitudinal muscle fibres. After 15 Gy irradiation (both photon and proton), the slide shows notable muscle fibre degeneration with edema formation. Scale bars $=50 \mu \mathrm{m}$.

The first radiation induced damage that could be observed in the brain is the formation of extracellular edema due to the disruption of the blood-brain barrier. For zebrafish embryos, no brain damage was seen at the lowest dose level ( $5 \mathrm{~Gy}$ ), which is comparable to the absent of muscle damage in this group (Figure 6). After irradiation of 10 Gy and 15 Gy we could detect signs of edema, brain vacuolisation and cellular debris in the neural layer, which indicated the development of more serious necrosis at higher dose levels.

Figure 7 summarizes the numerical results of the scoring system after proton and photon irradiation at escalated doses compared to the control group.

Morphological malformations. Both, proton and photon irradiation resulted in numerous morphological malformations like shortening of the overall body length (Figure 8), reduction of the eye size, i.e. microphthalmia (Figure 9), or inhibition of yolk sac resorption and edema formation in the yolk sac (Figure 10). The degree of morphological deteriorations was normalized to the values of the control group. We found significant dose-dependent impairments after irradiation of 10 Gy and 15 Gy.

The values in the figures show both the frequency and severity of the malformations concerned. Time wise, each organ impairment appeared on the third dpi, and the difference between the observed groups did not significantly change on the last (120 hpf) day. Morphological malformations could be measured already at 10 Gy dose level for protons at both positions (mSOBP and plateau), and they showed significant deterioration at $15 \mathrm{~Gy}$ dose level for both radiation qualities.

Determination of proton $\mathrm{RBE}$ based on morphological malformations. Table II shows the RBE values that were calculated on basis of the different morphological parameters observed in zebrafish embryo at the $3^{\text {rd }}$ or $4^{\text {th }}$ dpi with protons and reference photons.

At lower doses (5-10 Gy) we detected mild morphological deteriorations compared to the unirradiated group. At 15 Gy dose level, based on the eye size the 


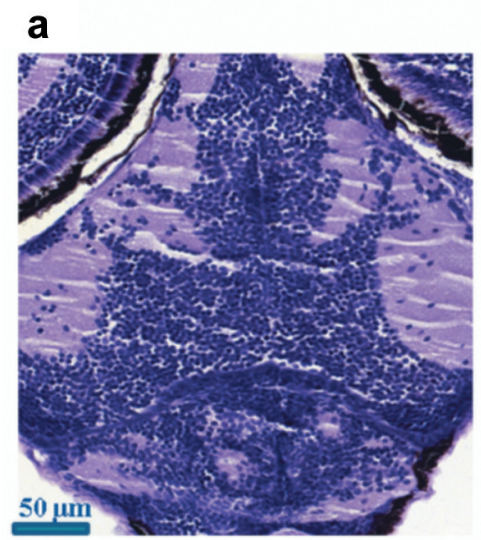

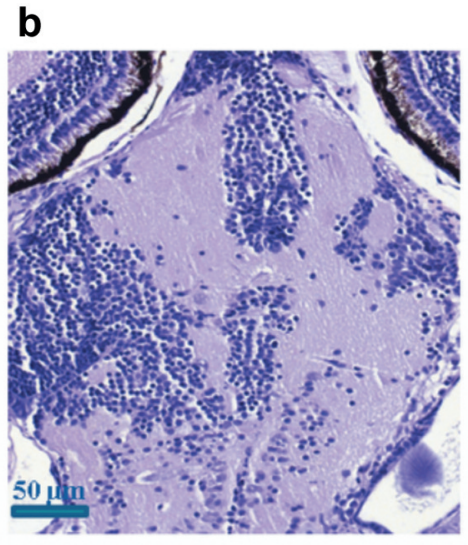

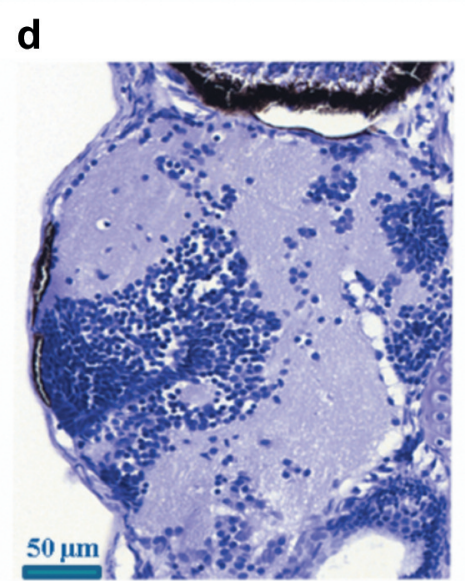

C

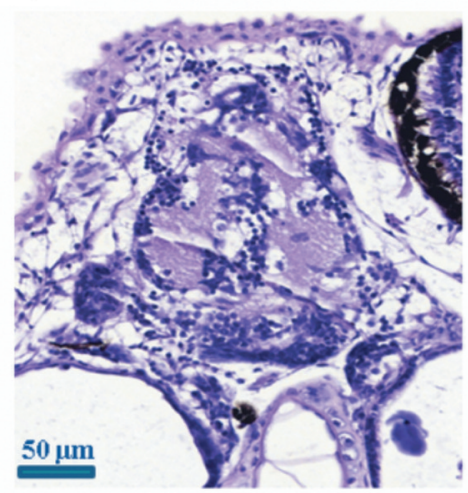

e

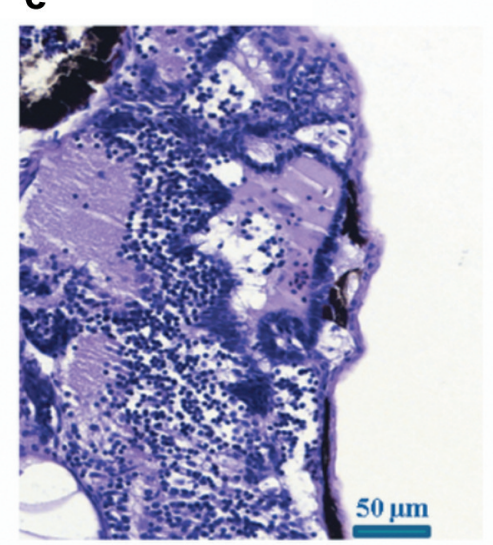

Figure 6. Dose-dependent changes in the brain after photon and proton irradiation. Hematoxylin and eosin stained coronal sections of a wild-type zebrafish brain at 120 h postfertilization (a) control, (b) 10 Gy photon irradiated, (c) 15 Gy photon irradiated, (d) 10 Gy proton irradiated and (e) 15 Gy proton irradiated. The pictures show areas and nuclei of the brain and the degree of necrosis. After irradiation of $10 \mathrm{~Gy}$ and $15 \mathrm{~Gy}$ (both photon and proton), the slide shows notable tissue degeneration and severe necrosis of the brain. Scale bars=50 $\mu \mathrm{m}$.

highest RBE values of $1.12 \pm 0.14$ at $96 \mathrm{hpf}$ at the $\mathrm{mSOBP}$ position and $1.10 \pm 0.12$ at $120 \mathrm{hpf}$ at the plateau region were calculated relative to reference photons. At this dose level the different radiation qualities did not result in distinguishable effects neither in relation to the yolk sac edema nor the shortening of body length.

\section{Discussion}

We irradiated the zebrafish embryos with protons at two positions along the proton depth dose curve, as well as with reference photons. Our aim was to define parameters and standards most suitable for radiobiology investigations on the zebrafish embryo model and unlock the potential of the proposed vertebrate model for the analysis of refined quantitative endpoints.

An established endpoint for assessing radiation-related DNA-DSB in cells is the measurement of $\gamma$-H2AX foci as a surrogate marker (26). Numerous in vitro experiments were performed to evaluate the number of induced DNA-DSB and the subsequent repair kinetics (27), and it was concluded that repair is delayed following proton irradiation. With our zebrafish embryo system, we confirmed the same difference between proton and photon irradiation. Similarly to in vitro systems, the maximum of the relative foci count was found 30 min after irradiation. In further time points the number of foci decreases, as the DNA-DSB repair progress (28). The foci number reaches control levels $24 \mathrm{~h}$ after photon irradiation. Despite similar kinetics, the number of foci is twice as high in the case of proton compared to photon exposure. Although the number of DNA-DSB per unit dose can be similar, the foci count per cell can differ significantly because of the differences in track structure and local energy deposition (27). This may result in more complex, proton-irradiation-induced damage which is harder to repair. Furthermore, similarly to rodent experiments, significant differences could be detected 


a
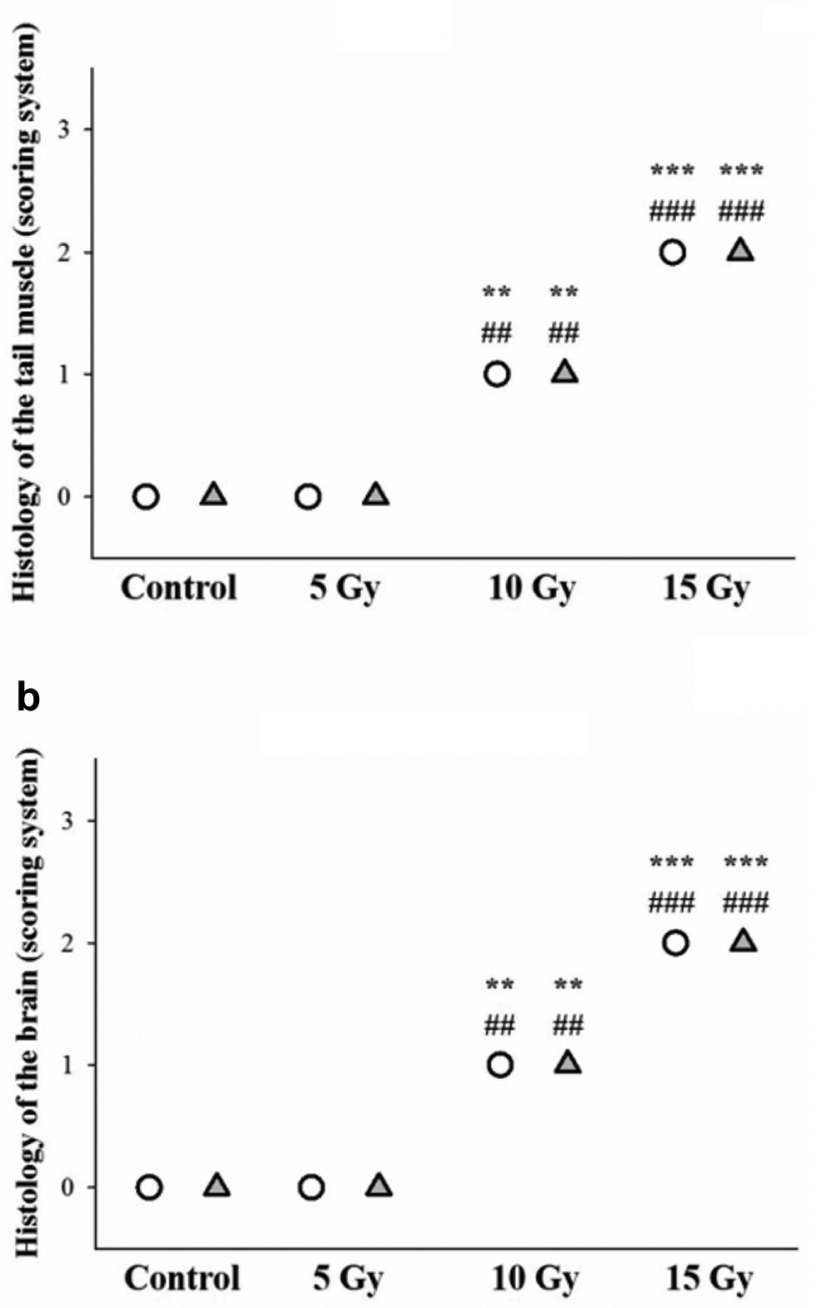

in DNA-DSB induction and repair kinetics in various tissues, i.e. in radiosensitive eye cells and less radiosensitive muscle cells due to their different genetics and microenvironmental backgrounds $(29,30)$. The comparability of the DNA repair kinetics to that observed in other animal species and in humans exposed to ionizing irradiation $(31,32)$.

Only a few articles report on histological deteriorations observed in zebrafish $(20,33,34)$ after ionizing radiation. For example, Geiger et al. (34) found a strong correlation between histo-morphological changes and increased cellular death, and observed changes in the eye and the brain of embryos irradiated at different hpf with doses up to $20 \mathrm{~Gy}$. Similarly to their findings, we also observed hypocellularity, disorganization of the cellular layers of the retina and lens opacification, as well as brain tissue perturbation at doses higher than $10 \mathrm{~Gy}$, irrespective of radiation quality. In addition, the newly introduced scoring system revealed mild changes in the eye

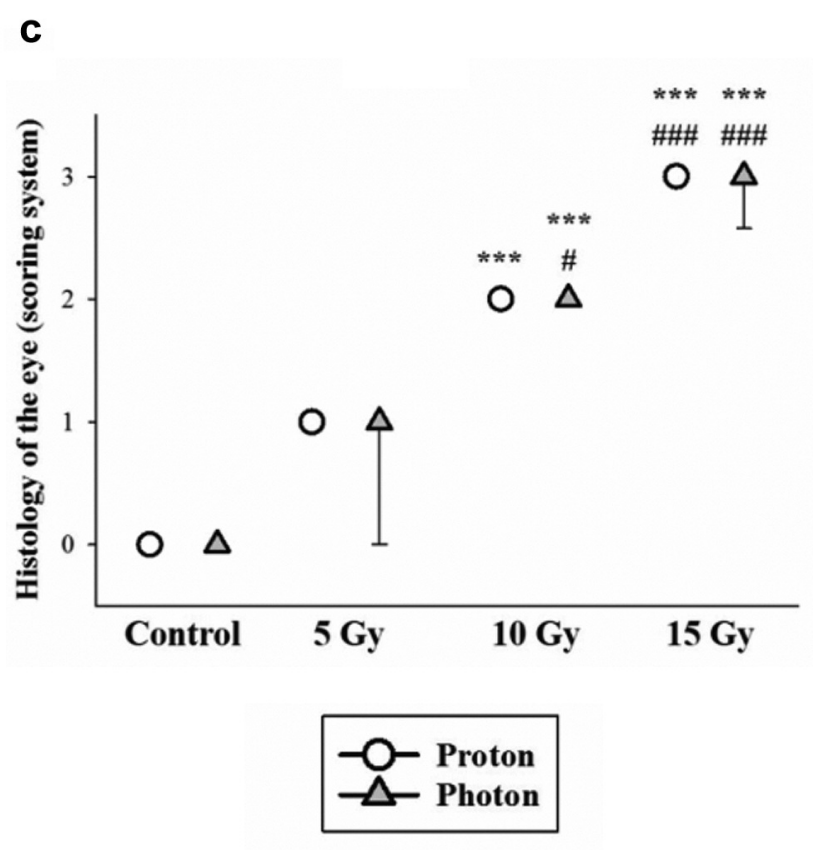

Figure 7. Summary of the histological evaluation of radiation induced damage in different tissues after photon (triangles) and proton (squares, averaging mid of spread out of Bragg peak and plateau) irradiation. The severity of damage was determined according to the system given in Table I for: (a) major edema formation with muscle fiber impairment after 15 Gy irradiation (both photon and proton), and (b) significant tissue lesions and severe necrosis of the brain after irradiation of $10 \mathrm{~Gy}$ and 15 Gy (both photon and proton), (c) there are signs of significant retinal layer and lens degeneration after photon irradiation of $10 \mathrm{~Gy}$, as well as photon and proton irradiation of $15 \mathrm{~Gy}$. ${ }^{*} p<0.05$, **p<0.01 and also $* * p<0.001$ relative to the control group, and ${ }^{\# \#} p<0.01$ as well as

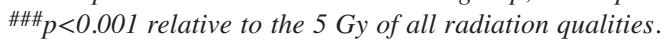

retina and lens, which could be detected already at 5 Gy dose level. Furthermore, in accordance with other in vivo models (35) the data derived from our model confirm that different tissues exhibit different radiation responses. The eye of the zebrafish embryo exhibited the highest radiation sensitivity among the investigated tissues. The zebrafish embryo model has proven to be useful for investigations on neurodevelopmental disorders and could replace the rodents in several aspects (35). For example, our dose-dependent histopathology findings of the brain are comparable to the results of Sahnoune et al., who established a juvenile rodent model and observed that fractionated irradiation of $4 \times 5$ Gy resulted in stunting of growth, as well as in changes in brain volume and axonal density and integrity (36). We could detect signs of edema, brain vacuolisation and cellular debris in the neural layer, which indicated the development of more serious necrosis, together with the shortening of the embryo at higher dose levels. 


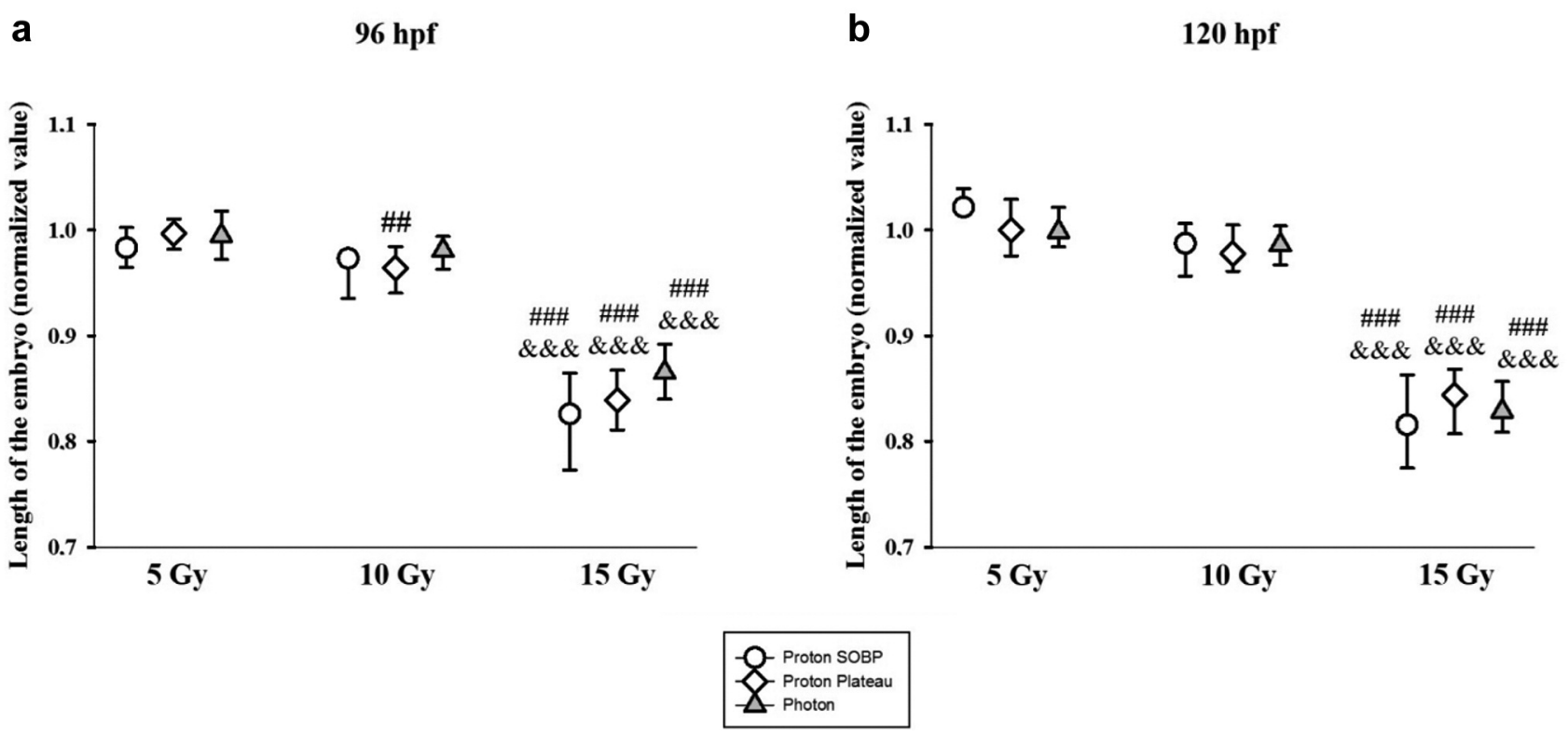

Figure 8. Embryo length normalized to the mean value of the control group. It significantly decreased after 15 Gy irradiation at both developmental stages and after treatment with protons at mid of spread out of Bragg peak (circle) or plateau (diamond) position and with photon reference

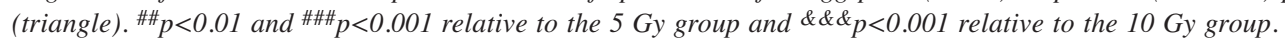

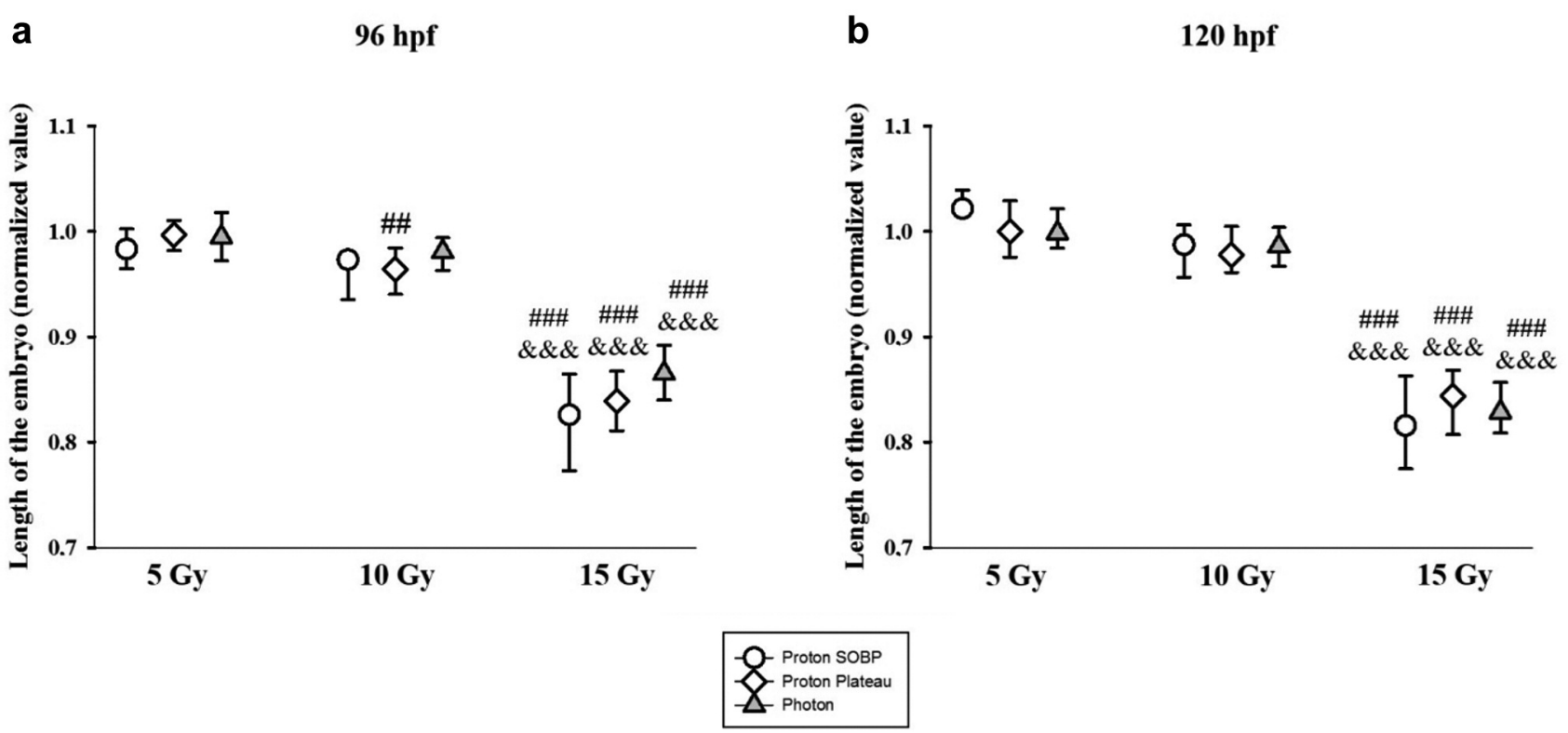

Figure 9. The size of the eye normalized to the mean value of the control group reduced significantly. The level of microphthalmia increased in a dosedependent manner after 10 Gy and 15 Gy irradiation. ${ }^{\#}<0.05$ and ${ }^{\# \#} p<0.001$ relative to the 5 Gy group and \&\&\& $p<0.001$ relative to the 10 Gy group.

Several reports have demonstrated that inflammation leads to edema formation as an acute radiation response $(18,37$ 39). In the previous evaluation (19), pericardial edema occurred in almost $100 \%$ and $90 \%$ of the embryo treated with proton and photon doses higher than $15 \mathrm{~Gy}$, respectively. In the present analysis, edema development could be detected both at micro- and macromorphological levels in different organs: in muscles, in the brain and in the yolk sac. Normally, the yolk sac gradually shrinks and completely resorbs within $120 \mathrm{hpf}$ (40), but irradiation may prevent its regression. This 
a

$96 \mathrm{hpf}$

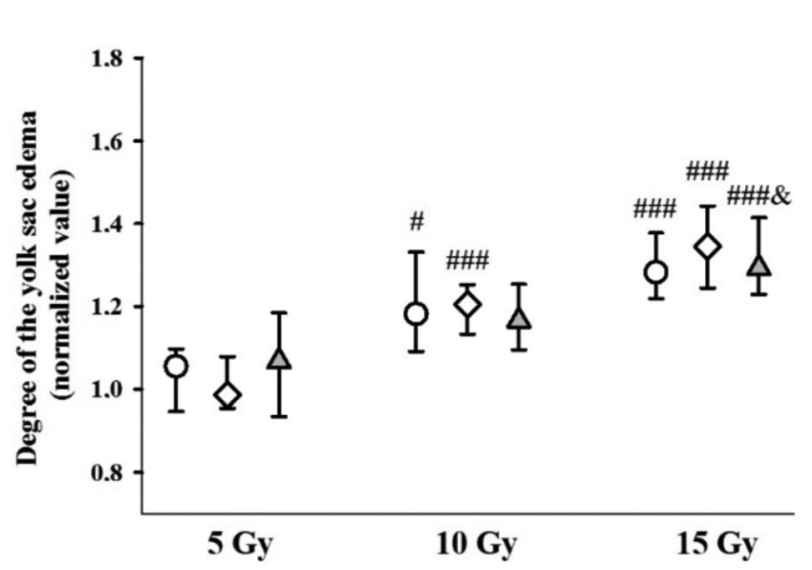

b 120 hpf
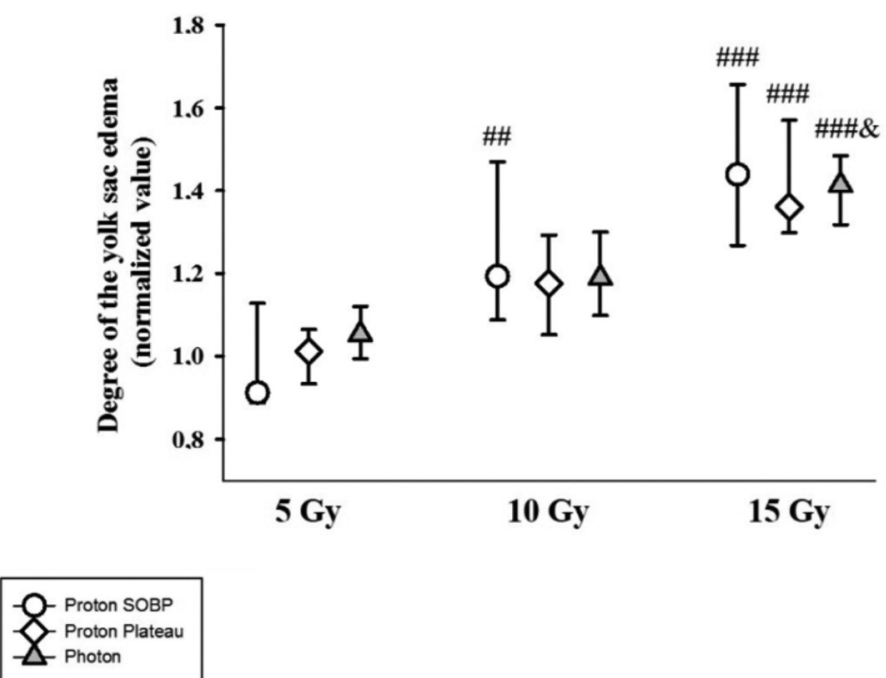

Figure 10. The yolk sac diameter increased significantly in a dose-dependent manner after 10 Gy and 15 Gy irradiation, at both developmental

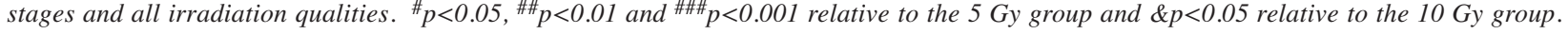

Table II. Dose-dependent relative biological effectiveness values calculated on basis of the mean values of the morphological deteriorations of embryos aged $96 \mathrm{~h}$ postfertilization ( $\mathrm{hpf}$ ) and $120 \mathrm{hpf}$ after irradiation with protons at mid of spread out of Bragg peak and the plateau position relative to $6 \mathrm{MV}$ photons.

\begin{tabular}{lrcc}
\hline Parameter & Age & SOBP position & Plateau position \\
\hline Body length & $96 \mathrm{hpf}$ & $1.05( \pm 0.08)$ & $1.04( \pm 0.08)$ \\
& $120 \mathrm{hpf}$ & $1.02( \pm 0.09)$ & $0.99( \pm 0.07)$ \\
Eye size & $96 \mathrm{hpf}$ & $1.12( \pm 0.19)$ & $1.08( \pm 0.19)$ \\
& $120 \mathrm{hpf}$ & $1.06( \pm 0.15)$ & $1.10( \pm 0.18)$ \\
Yolk sac edema & $96 \mathrm{hpf}$ & $0.99( \pm 0.17)$ & $1.01( \pm 0.18)$ \\
& $120 \mathrm{hpf}$ & $1.04( \pm 0.21)$ & $0.98( \pm 0.16)$ \\
\hline
\end{tabular}

allows us to follow edema formation by measuring the diameter of the retained yolk sac, that seem to provide a finer endpoint and more accurate results.

Furthermore, our measurements detected a notable reduction in body length, which suggests spinal cord curvature and growth delay. It is well known that different radiation qualities cause developmental deteriorations (41$44)$, but only a few studies measured the degree of spinal curvature $(19,20)$ and confirmed a linear dose dependent increase in severity on the fourth dpi at a dose level of 10 Gy or higher. Sayed and Mitani (45) showed spinal cord abnormality (body curvature) in the embryos of fish (Medaka) even after exposure to UV-A irradiation.
In the previous experimental campaign (19) the radiation effects of proton and photon beams were assessed, and RBE values were found to be in the range of 1.10-1.25 at a dose level of $20 \mathrm{~Gy}$, determined by survival-, and semiquantitative morphological deterioration assessment. In the present work, the measurement of yolk sac and eye diameters and embryonal body length after irradiation with 15 Gy resulted in RBE values around $1.0(0.98-1.12)$. The quantitative assessment of radiation induced morphological changes on zebrafish embryo provides valuable data on different normal tissue radiation sensitivity furthermore on dose, LET and tissue dependent biological effectiveness.

\section{Conclusion}

Our results prove the value of endpoint refinement for zebrafish embryo system in radiobiology experiments on accelerated particles (46). This reliable, reproducible and easily available in vivo model (47) could be implemented for quantitative analysis of the new particle acceleration and dose delivery methods that yield beams with non-clinical parameters, like the ultrahigh dose rate applied for Flash RT (48).

\section{Conflicts of Interest}

The Authors report no conflicts of interest.

\section{Authors' Contributions}

Conceptualization: K.H., Sz.B., T.T.; Data curation: Sz.B., T.T., R.P., A.L.Sz; Formal analysis: K.H., Sz.B., T.T., R.P., I.Z.Sz, Z.R., B.K.G, 
A.L.Sz; Funding acquisition: K.H.; Investigation: E.R.Sz., Sz.B., T.T.; Methodology: E.R.Sz, K.H., L.K, E.L, M.S; Project administration: E.R.SZ.; Resources: B.K.G., K.H., E.B., M.B., S.H., J.P.; Supervision: K.H., E.B., J.P.; Validation: Sz.B., T.T., Z.R..; Visualization: Sz.B., T.T.; Writing - original draft: Sz.B., T.T.; Writing - review \& editing: Sz.B., T.T., K.H., EB., J.P. All Authors read and approved the final manuscript.

\section{Acknowledgements}

The ELI-ALPS project (GINOP-2.3.6-15-2015-00001) is supported by the European Union and co-financed by the European Regional Development Fund and the European Union (ERC Advanced Grant ZfBrainReg). The project has received funding from Horizon 2020, the EU Framework Programme for Research and Innovation under Grant Agreements No. 871124 Laserlab-Europe and No. 730983 Inspire and from the Szeged Foundation for Cancer Research. The authors are very grateful to Erika Függ and Renáta Bozó for their invaluable assistance.

\section{References}

1 Dunne EM, Fraser IM and Liu M: Stereotactic body radiation therapy for lung, spine and oligometastatic disease: current evidence and future directions. Ann Transl Med 6, 2018. PMID: 30105233. DOI: $10.21037 / \mathrm{atm} .2018 .06 .40$

2 Wang S-J and Haffty B: Radiotherapy as a new player in immuno-oncology. Cancers 10, 2018. PMID: 30558196. DOI: $10.3390 /$ cancers 10120515

3 Durante M, Orecchia R and Loeffler JS: Charged-particle therapy in cancer: clinical uses and future perspectives. Nat Rev Clin Oncol 14: 483-495, 2017. PMID: 28290489. DOI: 10.1038/ nrclinonc. 2017.30

4 Baumann BC, Mitra N, Harton J, Xiao Y, Wojcieszynski A, Gabriel PE, Zhong H, Geng H, Doucette A, Wei JJ, O'Dwyer PJ, Bekelman JE and Metz JM: Comparative effectiveness of proton therapy versus photon therapy as part of concurrent chemoradiotherapy for locally advanced cancer. J Clin Oncol 37: 6521-6521, 2019. PMID: 31876914. DOI: 10.1200/JCO.2019.37.15_suppl.6521

5 Xiang MH, Chang DT and Pollom EL: Risk of subsequent cancer diagnosis in patients treated with 3D conformal, intensity modulated, or proton beam radiation therapy. J Clin Oncol 37: 1503-1503, 2019. DOI: 10.1200/JCO.2019.37.15_suppl.1503

6 Carante MP, Tello J and Ballarini F: Predicting biological effects along hadrontherapy dose profiles by the bianca biophysical model. Radiat Prot Dosimetry 183: 111-115, 2019. PMID: 30561725. DOI: $10.1093 / \mathrm{rpd} /$ ncy263

7 Saager M, Peschke P, Brons S, Debus J and Karger CP: Determination of the proton $\mathrm{RBE}$ in the rat spinal cord: is there an increase towards the end of the spread-out Bragg peak? Radiother Oncol J Eur Soc Ther Radiol Oncol 128: 115-120, 2018. PMID: 29573823. DOI: 10.1016/j.radonc.2018.03.002

8 Bayart E, Flacco A, Delmas O, Pommarel L, Levy D, Cavallone M, Megnin-Chanet F, Deutsch E and Malka V: Fast dose fractionation using ultra-short laser accelerated proton pulses can increase cancer cell mortality, which relies on functional PARP1 protein. Sci Rep 9: 10132, 2019. PMID: 31300704. DOI: 10.1038/s41598-019-46512-1

9 Favaudon V, Caplier L, Monceau V, Pouzoulet F, Sayarath M, Fouillade C, Poupon M-F, Brito I, Hupé P, Bourhis J, Hall J, Fontaine J-J and Vozenin M-C: Ultrahigh dose-rate FLASH irradiation increases the differential response between normal and tumor tissue in mice. Sci Transl Med 6: 245ra93, 2014. PMID: 25031268. DOI: 10.1126/scitranslmed.3008973

10 Fernandez-Palomo C, Fazzari J, Trappetti V, Smyth L, Janka H, Laissue $\mathrm{J}$ and Djonov V: Animal models in microbeam radiation therapy: a scoping review. Cancers 12, 2020. PMID: 32106397. DOI: $10.3390 /$ cancers 12030527

11 Hideghéty K, Szabó ER, Polanek R, Szabó Z, Ughy B, Brunner S and Tókés T: An evaluation of the various aspects of the progress in clinical applications of laser driven ionizing radiation. J Instrum 12: C03038-C03038, 2017. DOI: 10.1088/1748-0221/12/03/C03038

12 Gueulette J, Slabbert JP, Böhm L, De Coster BM, Rosier JF, Octave-Prignot M, Ruifrok A, Schreuder AN, Wambersie A, Scalliet $\mathrm{P}$ and Jones DT: Proton RBE for early intestinal tolerance in mice after fractionated irradiation. Radiother Oncol J Eur Soc Ther Radiol Oncol 61: 177-184, 2001. PMID: 11690684. DOI: 10.1016/s0167-8140(01)00446-7

13 Joiner MC and Denekamp J: The effect of small radiation doses on mouse skin. Br J Cancer Suppl 7: 63-66, 1986. PMID: 3459542.

14 Uzawa A, Ando K, Furusawa Y, Kagiya G, Fuji H, Hata M, Sakae T, Terunuma T, Scholz M, Ritter S and Peschke P: Biological intercomparison using gut crypt survivals for proton and carbon-ion beams. J Radiat Res (Tokyo) 48 Suppl A: A7580, 2007. PMID: 17513902. DOI: 10.1269/jrr.48.a75

15 Lühr A, Neubeck C von, Helmbrecht S, Baumann M, Enghardt $\mathrm{W}$ and Krause M: Modeling in vivo relative biological effectiveness in particle therapy for clinically relevant endpoints. Acta Oncol 56: 1392-1398, 2017. PMID: 28849720. DOI: 10.1080/0284186X.2017.1356468

16 Rasooly RS, Henken D, Freeman N, Tompkins L, Badman D, Briggs J and Hewitt AT: Genetic and genomic tools for zebrafish research: the NIH zebrafish initiative. Dev Dyn 228: 490-496, 2003. PMID: 14579387 . DOI: $10.1002 /$ dvdy.10366

17 Postlethwait JH, Woods IG, Ngo-Hazelett P, Yan YL, Kelly PD, Chu F, Huang H, Hill-Force A and Talbot WS: Zebrafish comparative genomics and the origins of vertebrate chromosomes. Genome Res 10: 1890-1902, 2000. PMID: 11116085. DOI: 10.1101/gr.164800

18 Plangár I, Szabó ER, Tókés T, Mán I, Brinyiczki K, Fekete G, Németh I, Ghyczy M, Boros $M$ and Hideghéty K: Radioneuroprotective effect of L-alpha-glycerylphosphorylcholine (GPC) in an experimental rat model. J Neurooncol 119: 253-261, 2014. PMID: 24880750. DOI: 10.1007/s11060-014-1489-z

19 Szabó ER, Brand M, Hans S, Hideghéty K, Karsch L, Lessmann E, Pawelke J, Schürer M and Beyreuther E: Radiobiological effects and proton RBE determined by wildtype zebrafish embryos. PloS One 13: e0206879, 2018. PMID: 30408095. DOI: 10.1371/journal.pone.0206879

20 Szabó ER, Reisz Z, Polanek R, Tőkés T, Czifrus Sz, Pesznyák Cs, Biró B, Fenyvesi A, Király B, Molnár J, Brunner Sz, Daroczi B, Varga Z and Hideghéty K: A novel vertebrate system for the examination and direct comparison of the relative biological effectiveness for different radiation qualities and sources. Int $\mathrm{J}$ Radiat Biol 94: 985-995, 2018. PMID: 30332320. DOI: 10.1080/09553002.2018.1511928

21 Brand M, Granato $M$ and Nüsslein-Vollhard C: Keeping and raising zebrafish. In: Zebrafish a practical approach. Oxford, Oxford University Press, pp 7-37, 2002.

22 Helmbrecht S, Baumann M, Enghardt W, Fiedler F, Krause M and Lühr A: Design and implementation of a robust and costeffective double-scattering system at a horizontal proton beamline. J Instrum 11: T11001-T11001, 2016. DOI: 10.1088/ 1748-0221/11/11/T11001 
23 Beyreuther E, Baumann M, Enghardt W, Helmbrecht S, Karsch L, Krause M, Pawelke J, Schreiner L, Schürer M, von Neubeck $\mathrm{C}$ and Lühr A: Research facility for radiobiological studies at the University Proton Therapy Dresden. Int J Part Ther 5: 172-182, 2018. PMID: 31773028. DOI: 10.14338/IJPT-18-00008.1

24 Schindelin J, Arganda-Carreras I, Frise E, Kaynig V, Longair M, Pietzsch T, Preibisch S, Rueden C, Saalfeld S, Schmid B, Tinevez J-Y, White DJ, Hartenstein V, Eliceiri K, Tomancak P and Cardona A: Fiji: an open-source platform for biologicalimage analysis. Nat Methods 9: 676-682, 2012. PMID: 22743772. DOI: $10.1038 /$ nmeth.2019

25 Tő́kés T, Varga G, Garab D, Nagy Z, Fekete G, Tuboly E, Plangár I, Mán I, Szabó RE, Szabó Z, Volford G, Ghyczy M, Kaszaki J, Boros $\mathrm{M}$ and Hideghéty K: Peripheral inflammatory activation after hippocampus irradiation in the rat. Int J Radiat Biol 90: 1-6, 2014. PMID: 23968122. DOI: 10.3109/09553002.2013.836617.

26 Hernández L, Terradas M, Martín Flix M, Tusell L and Genescà A: Highly sensitive automated method for DNA damage assessment: gamma-H2AX foci counting and cell cycle sorting. Int J Mol Sci 14: 15810-15826, 2013. PMID: 23903043. DOI: 10.3390/ijms140815810.

27 Paganetti H: Proton relative biological effectiveness - uncertainties and opportunities. Int J Part Ther 5: 2-14, 2018. PMID: 30370315. DOI: 10.14338/IJPT-18-00011.1.

28 Rothkamm K and Horn S: gamma-H2AX as protein biomarker for radiation exposure. Ann Ist Super Sanita 45: 265-271, 2009. PMID: 19861731.

29 Firsanov D, Vasilishina A, Kropotov A and Mikhailov V: Dynamics of $\gamma \mathrm{H} 2 \mathrm{AX}$ formation and elimination in mammalian cells after X-irradiation. Biochimie 94: 2416-2422, 2012. PMID: 22766016. DOI: 10.1016/j.biochi.2012.06.019.

30 Deycmar S, Faccin E, Kazimova T, Knobel PA, Telarovic I, Tschanz F, Waller V, Winkler R, Yong C, Zingariello D and Pruschy M: The relative biological effectiveness of proton irradiation in dependence of DNA damage repair. Br J Radiol, 2019. PMID: 31687835 . DOI: 10.1259/bjr.20190494.

31 Moroni M, Maeda D, Whitnall M, Bonner W and Redon C: Evaluation of the gamma-H2AX assay for radiation biodosimetry in a swine model. Int J Mol Sci 14: 14119-14135, 2013. PMID: 23880859. DOI: 10.3390/ijms 140714119 .

32 Redon CE, Nakamura AJ, Gouliaeva K, Rahman A, Blakely WF and Bonner WM: The use of gamma-H2AX as a biodosimeter for total-body radiation exposure in non-human primates. PLoS One 5: e15544, 2010. PMID: 21124906. DOI: 10.1371/journal.pone. 0015544.

33 Daroczi B, Kari G, McAleer MF, Wolf JC, Rodeck U and Dicker AP: In vivo radioprotection by the fullerene nanoparticle DF-1 as assessed in a zebrafish model. Clin Cancer Res Off J Am Assoc Cancer Res 12: 7086-7091, 2006. PMID: 17145832. DOI: 10.1158/1078-0432.CCR-06-0514.

34 Geiger GA, Parker SE, Beothy AP, Tucker JA, Mullins MC and Kao GD: Zebrafish as a "Biosensor"? Effects of ionizing radiation and amifostine on embryonic viability and development. Cancer Res 66: 8172-8181, 2006. PMID: 16912196. DOI: 10.1158/00085472.CAN-06-0466.

35 Lindsay KJ, Coates PJ, Lorimore SA and Wright EG: The genetic basis of tissue responses to ionizing radiation. $\mathrm{Br} \mathrm{J}$ Radiol 80 Spec No 1: S2-6, 2007. PMID: 17704322. DOI: $10.1259 / \mathrm{bjr} / 60507340$.

36 Chaudhary P, Marshall TI, Currell FJ, Kacperek A, Schettino G and Prise KM: Variations in the processing of DNA double- strand breaks along $60-\mathrm{MeV}$ therapeutic proton beams. Int $\mathrm{J}$ Radiat Oncol Biol Phys 95: 86-94, 2016. PMID: 26452569. DOI: 10.1016/j.ijrobp.2015.07.2279.

37 Tofilon PJ and Fike JR: The radioresponse of the central nervous system: a dynamic process. Radiat Res 153: 357-370, 2000. PMID: 10798963. DOI: 10.1667/0033-7587(2000)153[0357:troten]2.0.co;2

38 O'Connor MM and Mayberg MR: Effects of radiation on cerebral vasculature: a review. Neurosurgery 46: 138-151, 2000. PMID: 10626944. DOI: 10.1093/neurosurgery/46.1.138

39 Lafuente JV, Pouschman E, Cervós-Navarro J, Sharma HS, Schreiner C and Korves M: Dynamics of tracer distribution in radiation induced brain oedema in rats. Acta Neurochir Suppl (Wien) 51: 375-377, 1990. PMID: 2089944. DOI: 10.1007/9783-7091-9115-6_126

40 Parichy DM, Elizondo MR, Mills MG, Gordon TN and Engeszer RE: Normal table of post-embryonic zebrafish development: staging by externally visible anatomy of the living fish. Dev Dyn Off Publ Am Assoc Anat 238: 2975-3015, 2009. PMID: 19891001. DOI: $10.1002 /$ dvdy.22113

41 Dong Q, Svoboda K, Tiersch TR and Todd Monroe W: Photobiological effects of UVA and UVB light in zebrafish embryos: evidence for a competent photorepair system. J Photochem Photobiol B 88: 137-146, 2007. PMID: 17716904. DOI: 10.1016/j.jphotobiol.2007.07.002

42 Zhao W, Hu N, Ding D, Long D, Li S, Li G and Zhang H: Developmental toxicity and apoptosis in zebrafish embryos induced by low-dose $\gamma$-ray irradiation. Environ Sci Pollut Res 26: 38693881, 2019. PMID: 30539402. DOI: 10.1007/s11356-018-3893-y

43 Barrett C, Hellickson I, Ben-Avi L, Lamb D, Krahenbuhl M and Cerveny KL: Impact of low-level ionizing radiation on cell death during zebrafish embryonic development: Health Phys 114: 421428, 2018. PMID: 29481533. DOI: 10.1097/HP.0000000000000788

44 Zhou R, Si J, Zhang H, Wang Z, Li J, Zhou X, Gan L and Liu Y: The effects of $x$-ray radiation on the eye development of zebrafish. Hum Exp Toxicol 33: 1040-1050, 2014. PMID: 24522107. DOI: $10.1177 / 0960327114522278$

45 Sayed AE-DH and Mitani H: The notochord curvature in medaka (Oryzias latipes) embryos as a response to ultraviolet A irradiation. J Photochem Photobiol B 164: 132-140, 2016. PMID: 27668833. DOI: 10.1016/j.jphotobiol.2016.09.023

46 Rösch TF, Szabó Z, Haffa D, Bin J, Brunner S, Englbrecht FS, Friedl AA, Gao Y, Hartmann J, Hilz P, Kreuzer C, Lindner FH, Ostermayr TM, Polanek R, Speicher M, Szabó ER, Taray D, Tőkés T, Würl M, Parodi K, Hideghéty K and Schreiber J: A feasibility study of zebrafish embryo irradiation with laseraccelerated protons. Rev Sci Instrum 91: 063303, 2020. PMID: 32611048. DOI: 10.1063/5.0008512

47 Epperly MW, Bahary N, Quader M, Dewald V and Greenberger JS: The zebrafish - Danio rerio - is a useful model for measuring the effects of small-molecule mitigators of late effects of ionizing irradiation. In Vivo 26(6): 889-897, 2012. PMID: 23160669.

48 Beyreuther E, Brand M, Hans S, Hideghéty K, Karsch L, Leßmann E, Schürer M, Szabó ER and Pawelke J: Feasibility of proton FLASH effect tested by zebrafish embryo irradiation. Radiother Oncol J Eur Soc Ther Radiol Oncol 139: 46-50, 2019. PMID: 31266652. DOI: 10.1016/j.radonc.2019.06.024.

Received July 7, 2020

Revised September 17, 2020

Accepted September 23, 2020 